\title{
Traditional Chinese Medicine Shen-Yuan-Dan (SYD) Improves Hypoxia-Induced Cardiomyocyte Apoptosis in Neonatal Rats by Upregulating miR-24/Bim Pathway
}

\author{
Fuyong Chu, ${ }^{1}$ Xue Yan, ${ }^{2}$ Xingjiang Xiong, ${ }^{3}$ Mingxue Zhou $\mathbb{D}^{4},{ }^{4}$ Yupei Tan, ${ }^{1}$ Yixuan Li, ${ }^{5}$ \\ Wei Liu $\mathbb{D}^{1}{ }^{1}$ and Hongxu Liu $\mathbb{D}^{1}$ \\ ${ }^{1}$ Department of Cardiology, Beijing Hospital of Traditional Chinese Medicine, Capital Medical University, Beijing 100010, China \\ ${ }^{2}$ Department of Psychology and Sleep Medicine, Guang'anmen Hospital, China Academy of Chinese Medical Sciences, \\ Beijing 100053, China \\ ${ }^{3}$ Department of Cardiology, Guang'anmen Hospital, China Academy of Chinese Medical Sciences, Beijing 100053, China \\ ${ }^{4}$ Beijing Hospital of Traditional Chinese Medicine, Capital Medical University, Beijing Institute of Traditional Chinese Medicine, \\ Beijing, China \\ ${ }^{5}$ Department of Traditional Chinese Medicine, Community Healthcare Center of Shangzhuang Town, Haidian District, \\ Beijing 100094, China
}

Correspondence should be addressed to Wei Liu; lvzyxxg@163.com and Hongxu Liu; lhxcardiology1@163.com

Received 30 July 2021; Revised 14 September 2021; Accepted 18 December 2021; Published 3 February 2022

Academic Editor: Hong Chang

Copyright (c) 2022 Fuyong Chu et al. This is an open access article distributed under the Creative Commons Attribution License, which permits unrestricted use, distribution, and reproduction in any medium, provided the original work is properly cited.

Background: Acute myocardial infarction (AMI) is the leading cause of malignant arrhythmia, heart failure, and sudden death. However, safe and effective drugs for the treatment of AMI are unavailable to date. The present study aimed to investigate the role of traditional Chinese medicine shen-yuan-dan (SYD) in hypoxia-induced cardiomyocyte apoptosis in neonatal rats. In addition, the study explored the possible mechanism through which SYD could reduce myocardial ischemia apoptosis and regulate the expression of the miR-24/Bim pathway. Methods: Hypoxia-induced neonatal rat cardiomyocytes were used for the experiments. These cardiomyocytes were transfected with an miR-24 mimic and an miR-24 inhibitor and then cocultured with SYD-containing serum. MTT and lactate dehydrogenase (LDH) assays, AnnexinV/PI double staining, flow cytometry, and TUNEL staining were used to determine the cell viability and apoptosis under hypoxic conditions. Furthermore, the expression level of Bim in the hypoxia-induced cardiomyocytes was determined through western blotting and quantitative real-time polymerase chain reaction. Results: After $48 \mathrm{~h}$ of hypoxia, LDH and creatine phosphokinase (CPK) activities increased, cell viability decreased, and miR-24 expression upregulated in the cardiomyocytes. SYD alleviated hypoxia-induced cardiomyocyte injury, decreased LDH and CPK activities, increased cell viability, and reduced apoptosis in the neonatal rat cardiomyocytes. Moreover, SYD could upregulate miR-24 expression and downregulate Bim expression. Upregulation of miR-24 expression significantly enhanced the effect of SYD, thereby improving myocardial cell apoptosis. Dual-luciferase reporter assay and western blot analysis confirmed that Bim was a direct target of miR-24. Conclusion: SYD treatment reduces hypoxia-induced myocardial apoptosis by upregulating miR-24 expression. This study provides new insights into the molecular mechanism underlying the therapeutic potential of SYD in promoting the recovery of myocardial function and delaying the incidence of heart failure.

\section{Introduction}

Acute myocardial infarction (AMI) corresponds to acute ischemic myocardial necrosis [1]. It is a severe coronary heart disease, which is characterized by a drastic reduction or interruption in blood supply to the coronary artery, resulting in severe and long-term ischemia of the corresponding myocardium, culminating in myocardial necrosis. AMI is also characterized by acute onset and high mortality. Additionally, it is the leading cause of malignant arrhythmia, 
heart failure, and sudden death. Studies have indicated that approximately 3.5 million people die from cardiovascular diseases annually in China, of which the number of myocardial infarction (MI) cases is approximately 1 million [2]. AMI has become the leading cause of death in China.

Apoptosis is a vital pathological mechanism of early cell injury after MI [3]. Extensive cardiomyocyte apoptosis can be observed during both sustained myocardial ischemia after infarction and the ischemia-reperfusion period, and the increased apoptosis of cardiomyocyte eventually promotes the occurrence of heart failure. Therefore, for terminally differentiated cardiomyocytes lacking the regenerative capacity, developing strategies to decrease apoptosis of myocardial cells after MI is crucial for promoting the recovery of myocardial function and delaying the heart failure incidence after MI.

Previous studies suggest that the Bcl-2 homology domain 3 (BH3)-only pro-protein, namely Bim, is the pivotal regulatory protein in apoptosis, which can suppress prosurvival proteins or activate pro-apoptotic proteins to initiate the apoptosis pathway in response to adverse stimuli $[4,5]$. Moreover, an in vitro study has revealed that hypoxia with low glucose can distinctly promote Bim expression and induce cardiomyocyte apoptosis [6]. Bim1 triggers apoptosis by inhibiting the $\mathrm{Bcl}-2$ anti-apoptotic function and/or causing direct activation of Bax, leading to cytochrome $\mathrm{c}$ release and apoptotic signaling pathway activation [7].

MicroRNAs (miRNAs or miRs), approximately 18-24 nucleotides in length, belong to a class of evolutionarily conserved endogenous noncoding single-stranded small RNA molecules that regulate gene expression by binding to the $3^{\prime}$ UTR within target mRNAs to inhibit translation or degrade target messenger RNAs [8]. miR-24 is expressed highly in various tissues and is involved in the occurrence and development of several diseases, such as heart failure, oral cancer, hyperglycemia, and Alzheimer's disease [9]. Studies have shown that miR-24 is highly expressed in the mammalian myocardial tissues and is significantly upregulated in the early stage of myocardial ischemia in mice. It also participates in the self-repair process of ischemic myocardium by regulating the activation of its target gene Bim and its downstream mitochondrial apoptotic signaling pathway $[10,11]$. In addition, our previous clinical study demonstrated a significant negative correlation of miR-24 expression in peripheral blood of patients having acute coronary syndrome with the inflammatory and apoptotic factors [12]. Thus, we assume that miR-24 is closely related to coronary heart disease (CHD) pathogenesis and plays a crucial regulatory role in myocardial ischemia pathogenesis.

The Qi tonifying and blood stasis eliminating formulation, shen-yuan-dan (SYD), is a commonly used traditional Chinese medicine (TCM), which is used to treat angina pectoris [13]. In our previous study, we used a Waters ultra-high-performance liquid chromatography-tandem mass spectrometer (UPLC-MS/MS) equipped with a HESIII probe to analyze SYD components and found that the total ion chromatograms of SYD comprise tetrahydropalmatine, harpagoside, salvianic acid $\mathrm{A}$, salvianolic acid $\mathrm{B}$, and tanshinone IIA [14] (Table 1 presents the main chemical components, area of application, and dosage). Our previous studies have shown that SYD can reduce the MI area, myocardial cell injury, and apoptosis in rats with AMI, as well as play a myocardial protective role by upregulating miR-24 expression and interfering with the mitochondrial apoptosis signaling pathway [42]. However, its effect and mechanism of action on hypoxia-induced neonatal rat cardiomyocyte apoptosis in vitro remain unclear. Therefore, the present study attempted to investigate the effect of SYD on hypoxia-induced cardiomyocyte apoptosis and explore whether SYD can reduce ischemic myocardial apoptosis and confer myocardial protection by regulating miR-24/Bim pathway expression.

\section{Materials and Methods}

2.1. Reagents and Instruments. TRIzol, Lipofectamin ${ }^{\mathrm{TM}} 2000$ transfection Kit (\#11668027), and Power SYBR Green PCR Kit (\#4309155) were purchased from Invitrogen, USA. DualLuciferase Reporter Assay System and M-MLV reverse transcriptase were obtained from Promega. The mirVana ${ }^{\mathrm{TM}}$ qRT-PCR miRNA Detection Kit (\#AM1558) was acquired from Life Technologies, USA. The miR-24 mimics and inhibitors were synthesised by the GenePharma Company (Shanghai, China). MTT Detection Kit and TUNEL Apoptosis Detection Kit were procured from Beyotime Institute of Biotechnology (Beijing, China). Lactate dehydrogenase $(\mathrm{LDH})$ and creatine phosphokinase $(\mathrm{CPK})$ detection kits were procured from the Nanjing Jiancheng Bioengineering Institute, China. Annexin V Apoptosis Detection Kit was purchased from BD Biosciences, USA. Bim and GAPDH antibodies were purchased from Cell Signaling. The horseradish peroxidase-labelled secondary antibody was procured from Santa Cruz Biotechnology. The enzyme label instrument, Tecan Infinite M1000, was procured from Switzerland. The ABI 7300 real-time PCR instrument was purchased from Applied Biosystems, USA. The NanoDrop 2000 spectrophotometer was purchased from Thermo, USA. The FacsCalibur flow cytometer was purchased from BD Biosciences, USA. The inverted fluorescence microscope was purchased from Olympus, Japan. The upfront fluorescence microscope was purchased from Leica, Germany.

\subsection{Preparation of SYD Aqueous Extracts and Pharmacological} Serum. SYD comprises eight crude medicinal agents, namely, Salvia miltiorrhiza Bge $(15 \mathrm{~g})$, Astragalus membranaceus Bge (12 g), Radix Pilose Asiabell (10 g), Radix Scrophulariae (5g), Hirudo nipponica (Whitman) (3g), Lumbricus (5g), Eupolyphaga sinensis (Walker) (5g), and Rhizoma Corydalis (5 g) (Table 1). All medicinal herbs were purchased from Beijing Xinglin Pharmaceutical Co. (Beijing, China) and were authenticated by Kechen Mao, a professional herbalist from Beijing TCM Hospital, Capital Medical University. A mixture of all these herbs was soaked in distilled water for $30 \mathrm{~min}$, boiled in 10 volumes of water ( $\mathrm{v} /$ w) for $1 \mathrm{~h}$, and extracted thrice. The filtered and mixed solution from three decoctions was vacuum concentrated using a rotary evaporator to a final concentration of $1 \mathrm{~g} / \mathrm{ml}$ 
Table 1: Composition of shen-yuan-dan.

\begin{tabular}{|c|c|c|c|c|c|c|c|}
\hline English name & Latin name & $\begin{array}{l}\text { Chinese } \\
\text { name }\end{array}$ & $\begin{array}{c}\text { Place of } \\
\text { production } \\
\text { (province) }\end{array}$ & $\begin{array}{l}\text { Collecting } \\
\text { time } \\
\text { (season) }\end{array}$ & Part used & $\begin{array}{l}\text { Amount } \\
\text { used }(g)\end{array}$ & TCM efficacy \\
\hline $\begin{array}{l}\text { Salvia } \\
\text { miltiorrhiza Bge }\end{array}$ & Radix Salviae & Danshen & $\begin{array}{l}\text { Hubei, } \\
\text { Henan }\end{array}$ & $\begin{array}{l}\text { Spring and } \\
\text { autumn }\end{array}$ & $\begin{array}{l}\text { Root and } \\
\text { rootstock }\end{array}$ & 15 & $\begin{array}{l}\text { Activating blood } \\
\text { and removing } \\
\text { stasis; inducing } \\
\text { menstruation to } \\
\text { relieve menalgia; } \\
\text { eliminating the } \\
\text { heart-fire; } \\
\text { cooling-blood }\end{array}$ \\
\hline
\end{tabular}

Astragalus

membranaceus

Bge

Radix Pilose

Asiabell

\section{Astragalus \\ propinquus}

Codonopsis Radix

Dangshen

Gansu

Autumn

Root

10

Radix

Scrophulariae
Scrophularia ningpoensis
Xuanshen
Invigorating Qi

for strengthening

superficies;

diuresis;

promoting

granulation

Tonifying

middle-Jiao and

Qi; promote the production of

body fluid;

strengthening

spleen; and

tonifying lung

Removing

pathogenic heat

from blood;

nourishing yin

for lowering fire;

clearing toxic

material,

dispersing mass
Pharmacological activity

Inhibiting increase of blood serum level of triglycerides [15], reversing renal

injury induced [16], reversing cerebral ischemiareperfusion injury [17], relieving myocardial ischemia

[18], ameliorating

diabetic vascular injury [19] Inhibiting myocardial ischemiareperfusion injury, myocardial hypertrophy, vascular endothelial dysfunction, coronary heart disease, atherosclerosis, cardiac fibrosis, viral myocarditis, and diabetes mellitus [20], exerting antioxidant activity [21]

Preventing hypoxiainduced platelet activation and resultant

procoagulant state [22], promoting mouse immune function [23], inhibiting the development of diet-induced obesity and hyperlipidemia [24], and relieving myocardial ischemiareperfusion injury

Reversing heart and cerebral ischemia/ reperfusion injury [26], relieving diabetic nephropathy [27], inhibiting the ventricular remodeling induced by hypertension [28], attenuating arteriosclerosis [29] 
TABLE 1: Continued.

\begin{tabular}{|c|c|c|c|c|c|c|c|c|}
\hline English name & Latin name & $\begin{array}{c}\text { Chinese } \\
\text { name }\end{array}$ & $\begin{array}{l}\text { Place of } \\
\text { production } \\
\text { (province) }\end{array}$ & $\begin{array}{l}\text { Collecting } \\
\text { time } \\
\text { (season) } \\
\end{array}$ & Part used & $\begin{array}{l}\text { Amount } \\
\text { used }(g)\end{array}$ & TCM efficacy & $\begin{array}{c}\text { Pharmacological } \\
\text { activity }\end{array}$ \\
\hline $\begin{array}{l}\text { Hirudo } \\
\text { nipponica } \\
\text { (Whitman) }\end{array}$ & $\begin{array}{l}\text { Whitmania } \\
\text { pigra } \\
\text { Whitman }\end{array}$ & Shuizhi & Shandong & $\begin{array}{l}\text { Summer } \\
\text { and } \\
\text { autumn }\end{array}$ & $\begin{array}{l}\text { All parts } \\
\text { of the } \\
\text { Hirudo }\end{array}$ & 3 & $\begin{array}{l}\text { Broken blood } \\
\text { stasis, pursue } \\
\text { action of silt, } \\
\text { stimulate the } \\
\text { menstrual flow }\end{array}$ & $\begin{array}{c}\text { Promoting blood } \\
\text { circulation and } \\
\text { removing stasis [30], } \\
\text { relieving } \\
\text { atherosclerosis [31], } \\
\text { alleviating } \\
\text { thrombus burden } \\
\text { [32], improving } \\
\text { blood hyperviscosity } \\
\text { and related } \\
\text { metabolic disorders } \\
{[33]}\end{array}$ \\
\hline Lumbricus & Pheretima & Dilong & $\begin{array}{l}\text { North } \\
\text { China }\end{array}$ & $\begin{array}{l}\text { Summer } \\
\text { and } \\
\text { autumn }\end{array}$ & All parts & 5 & $\begin{array}{l}\text { Dredging } \\
\text { collaterals, } \\
\text { relieving cough } \\
\text { and asthma, } \\
\text { clearing heat, } \\
\text { diuretic }\end{array}$ & $\begin{array}{l}\text { Exerting anti- } \\
\text { thrombus [34], } \\
\text { reversing } \\
\text { mitochondrial } \\
\text { injury and pro- } \\
\text { fibrotic events [35], } \\
\text { protecting brain } \\
\text { microvascular } \\
\text { endothelial cells } \\
\text { after oxygen-glucose } \\
\text { deprivation/ } \\
\text { reperfusion [36] }\end{array}$ \\
\hline $\begin{array}{l}\text { Eupolyphaga } \\
\text { sinensis } \\
\text { (Walker) }\end{array}$ & $\begin{array}{l}\text { Eupolyphaga } \\
\text { seu } \\
\text { Steleophaga }\end{array}$ & Tubiechong & $\begin{array}{l}\text { North } \\
\text { China }\end{array}$ & $\begin{array}{l}\text { Summer } \\
\text { and } \\
\text { autumn }\end{array}$ & All parts & 5 & $\begin{array}{l}\text { Broken blood } \\
\text { stasis, reunion of } \\
\text { fractured } \\
\text { tendons and } \\
\text { bones }\end{array}$ & $\begin{array}{c}\text { Relieving } \\
\text { atherosclerosis [37], } \\
\text { exerting } \\
\text { antiangiogenesis } \\
{[38]}\end{array}$ \\
\hline $\begin{array}{l}\text { Rhizoma } \\
\text { Corydalis }\end{array}$ & $\begin{array}{l}\text { Corydalis } \\
\text { Rhizoma }\end{array}$ & Yanhusuo & $\begin{array}{l}\text { Zhejiang; } \\
\text { Jiangsu }\end{array}$ & Summer & Tubers & 5 & $\begin{array}{c}\text { Removing blood } \\
\text { stasis; regulating } \\
\text { Qi; and relieve } \\
\text { pain }\end{array}$ & $\begin{array}{l}\text { Degrading the blood } \\
\text { clot and delaying the } \\
\text { plasma } \\
\text { recalcification time } \\
\text { [39], inhibiting } \\
\text { inflammation, } \\
\text { myocardial fibrosis, } \\
\text { and platelet } \\
\text { aggregation [40], } \\
\text { improving the } \\
\text { hypercoagulable } \\
\text { state [41] }\end{array}$ \\
\hline
\end{tabular}

(w/v), followed by centrifugation at $3000 \mathrm{rpm}$ for $30 \mathrm{~min}$, and finally stored at $-20^{\circ} \mathrm{C}$ for subsequent experiments. To obtain SYD pharmacological serum, $50 \mathrm{Wistar}$ rats (weight: 220-250 g), purchased from the Institute of Laboratory of Animal Sciences, China Academy of Medical Science (Beijing, China), were divided into two groups; one group was administered SYD $(6 \mathrm{~mL} / \mathrm{kg})$ and another group (control) was administered saline $(6 \mathrm{~mL} / \mathrm{kg})$ orally twice daily for five days. One hour after the final administration, rats from each group were anaesthetized. Then, blood was drawn from the abdominal aortic artery, and the blood samples were centrifuged at $3000 \mathrm{rpm}$ for $10 \mathrm{~min}$. Serum from each rat was collected and centrifuged at $1000 \mathrm{rpm}$ for another $10 \mathrm{~min}$. Individual serum samples from the same treatment group were combined in a $4 \mathrm{~mL}$ tube, inactivated at $56^{\circ} \mathrm{C}$ for $30 \mathrm{~min}$, and stored at $-20^{\circ} \mathrm{C}$ before processing. Prior to cellular experiments, sera of both SYD and control groups were diluted to $5 \%$ or $10 \%$ (v/v) with the DMEM/F12 culture medium.

2.3. Myocardial Cell Culture and Modeling. The heart of neonatal SD rats (1-3 days, Beijing Vitong Lihua Experimental Animal Co. Ltd, Certificate No. SCXK (Beijing) 2015-0007) was taken out under sterile conditions. The tissues were subjected to enzymatic digestion to obtain a single-cell suspension and separated using the differential adherent method to obtain purified cardiomyocytes. The cultivated cardiomyocytes were counted, $5 \times 10^{5} / \mathrm{mL}$ seed plates, and used for the experiments $48 \mathrm{~h}$ later. The 
cardiomyocytes were cultivated for $48 \mathrm{~h}$ and then cultured on low-glucose, serum-free DMEM for an additional $12 \mathrm{~h}$ to synchronise cell growth. The cardiomyocytes were cultivated for 12,24 , and $48 \mathrm{~h}$ in a $1 \%$ Air- $94 \% \mathrm{~N}_{2}-5 \% \mathrm{CO}_{2}$ incubator to establish a hypoxic injury model. Low-glucose DMEM in normal oxygen was used as a control group.

\subsection{Liposome-Mediated Chemical Synthesis of miR-24 and Its} Transfection into Cardiomyocytes. Cardiomyocytes were transfected with the chemically synthesised miR-24 mimic and inhibitor by using Lipofectamine ${ }^{\mathrm{TM}} 2000$, according to the manufacturer's instructions.

2.5. Experimental Grouping and Cell Processing. A total of five experimental groups were formed: (1) Normoxia; (2) hypoxia; (3) hypoxia + SYD; (4) hypoxia + SYD + miR-24 mimic; and (5) hypoxia + SYD + miR-24 inhibitor. The cardiomyocytes were cultivated for $48 \mathrm{~h}$, and then, the culture medium was changed to low-glucose, serum-free DMEM for another $12 \mathrm{~h}$ to synchronise cell growth. Then, the miR-24 mimics and inhibitors were transfected into the neonatal rat cardiomyocytes, cocultivated with SYD-containing serum DMEM for $30 \mathrm{~min}$, and then cultivated in a $1 \%$ Air-94\% $\mathrm{N}_{2}-5 \% \mathrm{CO}_{2}$ incubator for $48 \mathrm{~h}$ to establish the hypoxic injury model. Myocardial cells with $48 \mathrm{~h}$ of ischemia and hypoxia were collected for experimental observations.

2.6. Lactic Dehydrogenase and Creatine Phosphokinase Determination. LDH and CPK activities in the supernatant of myocardial cell culture medium were determined colorimetrically, and the effects of SYD serum on the degree of hypoxic myocardial cell injury were observed. Specific methods mentioned in the kit operation instructions were followed.

2.7. MTT Assay for Myocardial Cell Viability. Primarily cultivated cardiomyocytes were seeded in 96-well plates at a density of $3-4 \times 10^{5} / \mathrm{mL}(150 \mu \mathrm{L}$ per hole $)$. After $48 \mathrm{~h}$ of hypoxia, $15 \mu \mathrm{L}$ of MTT solution $(5 \mathrm{mg} / \mathrm{mL}$ ) was added to each well for further incubation at $37^{\circ} \mathrm{C}$ for $4 \mathrm{~h}$. After four hours, the supernatant was removed, $150 \mu \mathrm{L}$ dimethylsulfoxide (DMSO) was added to each well, and the plates were shaken for $10 \mathrm{~min}$ to allow the crystals to fully dissolve. The absorbance (OD) of the reaction mixture at $490 \mathrm{~nm}$ was recorded. The cell survival rate was the percentage of the absorbance value of the experimental group compared with that of the control group.

2.8. Detection of Cardiomyocyte Apoptosis through AnnexinV/PI Double Staining and Flow Cytometry. The cells were subjected to trypsin digestion and washed twice with PBS; approximately $3 \times 10^{5}$ cells were collected. The collected cells were suspended in $500 \mu \mathrm{L}$ Annexin V-binding buffer, followed by staining with $5 \mu \mathrm{L}$ AnnexinV-FITC and $5 \mu \mathrm{L}$ PI at room temperature in dark for $15 \mathrm{~min}$. Thereafter, the cell apoptosis was detected through flow cytometry. All the experiments were performed in triplicate.

2.9. Detection of Cardiomyocyte Apoptosis through TUNEL Staining. After hypoxia was induced, the original culture medium was discarded, and the cells were washed thrice with PBS. Then, the cells were fixed with $4 \%$ paraformaldehyde for $60 \mathrm{~min}$. Afterwards, 4\% paraformaldehyde was discarded, and the cells were washed with PBS, which was discarded prior to placing the cells in PBS containing $0.1 \%$ Triton X-100 to submerge them at the bottom of the board, and then, the cells were placed on ice for $2 \mathrm{~min}$. Then, TritonPBS was discarded, and the cells were washed twice with PBS. Subsequently, $50 \mu \mathrm{L}$ TUNEL working solution was added to each well of the plate, and the mixture was incubated at $37^{\circ} \mathrm{C}$ in dark for $1 \mathrm{~h}$. Five minutes before the endpoint, $50 \mu \mathrm{L}$ of DAPI solution was added to each well, followed by gentle mixing and incubation in the dark for $5 \mathrm{~min}$. Afterwards, the cells were washed thrice with PBS. The cells were sealed with fluorescent labels and observed through fluorescence microscopy. Five overlapping images (green + purple) were randomly captured from each sample to calculate the proportion of TUNEL-positive cells, which appeared as green fluorescent cells, whereas the remaining cells appeared as purple fluorescent cells.

2.10. Quantitative Real-Time PCR. Total RNA from the cardiomyocytes was extracted using TRIzol reagent, according to the manufacturer's instructions, and the $400 \mathrm{ng}$ RNA template was taken from each sample to synthesise cDNA. miR-24 expression was detected using the mirVana ${ }^{\mathrm{TM}}$ qRT-PCR miRNA Detection Kit. The expression of Bim was detected using the Power SYBR Green PCR Kit. U6 was used as an internal control of miR-24, and the mRNA level of Bim was normalised to that of GAPDH. The relative expression of mRNA in each sample was calculated using equation $2^{-\Delta \Delta C t}$. The primers were listed as follows:

\section{miR-24-F: 5'-GAGCTTGCCAGAGTATCCACG-3' miR-24-R: $5^{\prime}$-GCTATTGCCCAAGAGGTCGC-3' U6-F: $5^{\prime}$-CTTCACTGGGAAGTTCGGTC-3' U6-R: $5^{\prime}$-ACTTCCCTTAGGCATCCCA-3' Bim-F: 5'-CTCTTTAAGCCGTTAGCCC-3' Bim-R: 5'-GATCCTTGGACCGTCCTGTA-3' GAPDH-F: 5'-CTGCGGATTT GGACAGTTCC-3' GAPDH-R: 5'-ACTTCCTTCAGAGATCCCAT-3'}

2.11. Western Blot Analysis. The cells were subjected to trypsin digestion and then collected. RIPA lysate was added, lysed on ice for $30 \mathrm{~min}$, centrifuged at $12000 \mathrm{rpm}$ for $4 \mathrm{~min}$ at $4^{\circ} \mathrm{C}$, and the supernatant was collected. Protein concentration was determined using the BCA method. Subsequently, $50 \mu \mathrm{g}$ of protein lysates was separated through $10 \%$ SDS-PAGE and were then transferred to the PVDF membrane. After blocking the membrane with 5\% skimmed milk at room temperature for $1 \mathrm{~h}, \mathrm{GDPDH}$ or primary antibodies 
were added, followed by overnight incubation at $4^{\circ} \mathrm{C}$. After washing the membrane thrice with TBST buffer solution, horseradish peroxidase-labelled secondary antibodies were added, and the mixture was incubated at room temperature for $1 \mathrm{~h}$. The films were washed thrice with TBST and subjected to the ECL chemiluminescence assay; the images were captured using the Image-Pro plus 6.0 image analysis system.

2.12. Luciferase Reporter Assays. The full-length sequence amplification product of Bim gene $3^{\prime}$ UTR, which contained the predicted miR-24 targeting regions, was inserted into a PmirGLO expression vector (Bim-wt), and targeted mutation (Bim-mut) was performed for the target binding site of miR-24 and Bim gene predicted using a software (TargetScan 3.0). Then, Lipofectamine ${ }^{\mathrm{TM}} 2000$ was used to cotransfect the reporter plasmid and miR-24 mimic or its negative control (miR-24 mimic-NC) into HEK293T cells. Bim-wt and Bim-mut transfected cells were divided into three groups, namely, blank control, miR-24 mimic, and mimic negative control, with three duplicate wells in each group. After a $48 \mathrm{~h}$ incubation period, luciferase activity was detected using the Tecan M1000 multifunctional enzyme labelling instrument, according to the instructions provided in the double luciferase activity detection kit. Relative luciferase activity was calculated using the following formula: relative luciferase activity = firefly luciferase activity/sea kidney luciferase activity. The experiment was repeated three times.

\section{Statistical Analysis}

SPSS 15.0 software was used for data analyses. All data are presented as mean \pm SEM (standard error of mean) from at least three independent experiments. Differences between the groups were determined using the Student's $t$-test and one-way ANOVA. Statistical significance was considered at a $P$ value of $<0.05$.

\section{Results}

4.1. Effect of SYD on Morphology, Injury Degree, and Viability of the Hypoxia-Induced Cardiomyocyte. Cardiomyocyte morphology was found to change $48 \mathrm{~h}$ after hypoxia (Figure 1(a)); the morphology changed mainly from spindle to round or quasi-round. $\mathrm{LDH}$ and $\mathrm{CPK}$ activities increased (Figures 1(b) and 1(c)), cell survival rate decreased (Figure 1(d)), and miR-24 expression increased by $35 \%$ (Figure 1(e)). These results indicated that hypoxia induces myocardial cell injury and that miR-24 may play a role in hypoxia-induced myocardial cell injury.

Then, we observed the effect of SYD serum on hypoxiainduced myocardial cell injury and found that SYD could reduce the $\mathrm{LDH}$ and $\mathrm{CPK}$ activities of the hypoxic myocardial cells (Figures 1(b) and 1(c)) and increase the cell survival rate (Figure $1(\mathrm{~d})$ ). Interestingly, miR-24 level in the hypoxia + SYD group was upregulated by $67 \%$, as compared to that of the control (Figure 1(e)). This result suggested that
SYD can alleviate hypoxic myocardial cell injury, and SYD treatment can lead to upregulation of miR-24.

To determine whether miR-24 plays a role in SYDmediated protection to hypoxic myocardial cells, we transfected the miR-24 mimic and inhibitor into the cardiomyocytes and cocultivated with SYD-containing serum. The MTT assay showed that the viability of myocardial cells was further improved (Figure 1(d)) and the activities of LDH and CPK were further decreased (Figures 1(b) and 1(c)) in the miR-24 mimic transfection group. However, after miR24 inhibitor transfection, the viability of cells was slightly decreased (Figure $1(\mathrm{~d})$ ), and the activities of LDH and CPK were increased (Figures 1(b) and 1(c)) compared with those in the hypoxia + SYD group. These results indicated that upregulation of miR-24 can significantly enhance the protective effect of SYD in hypoxia-induced cardiomyocyte.

4.2. Effect of SYD on Apoptosis of Hypoxic-Induced Cardiomyocytes. To determine the effect of SYD and the role of miR-24 in hypoxia-induced cardiomyocyte apoptosis, we used flow cytometry and TUNEL methods to detect apoptosis. Flow cytometry indicated that after $48 \mathrm{~h}$ of hypoxia, the apoptosis rate of the cardiomyocytes was significantly increased, and SYD could effectively reduce the apoptosis rate of the cardiomyocytes. The apoptosis rate of the miR-24 mimic group was further reduced, whereas that of the miR24 inhibitor group was slightly increased compared with that of the hypoxia + SYD group (Figure 2(a)). Similar results were obtained through TUNEL staining. After transfection with the miR-24 mimic, the proportion of TUNEL-positive cells was significantly reduced, while transfection with the miR-24 inhibitor displayed the opposite effect (Figure 2(b)).

4.3. Effects of SYD on $m R N A$ and Protein Expression of Bim in the Hypoxic-Induced Cardiomyocytes. Western blot and qRT-PCR analysis showed that, after 48 hours of hypoxia, the Bim protein and mRNA expression were significantly increased and SYD could decrease the protein and mRNA expression of Bim. Compared with the hypoxia +SYD group, Bim protein and mRNA expression in the miR-24 mimic group were further decreased (Figures 3(a)-3(c)). These results suggest that SYD can improve hypoxia-induced cardiomyocyte apoptosis by upregulating miR-24 expression and inhibiting the Bim expression.

4.4. Luciferase Report Assay Showed Bim Was the Target Gene of miR-24. To elucidate the specific mechanism of action of miR-24, we predicted the target gene of miR-24 through TargetScan and identified Bim as the target gene of miR-24. The pmirGLO-report plasmid of wild-type and mutated $3^{\prime}$ UTR of Bim, which contained the binding sites of miR-24, was cloned downstream of the luciferase reporter gene vector. Additionally, cotransfection of the miR-24 mimic and the plasmid with the Bim-wt $3^{\prime}$ UTR inhibited the luciferase activity of the Bim gene. However, cotransfection of the miR-24 mimic and the plasmid with the Bim-mut $3^{\prime}$ UTR demonstrated no significant effect on the luciferase 


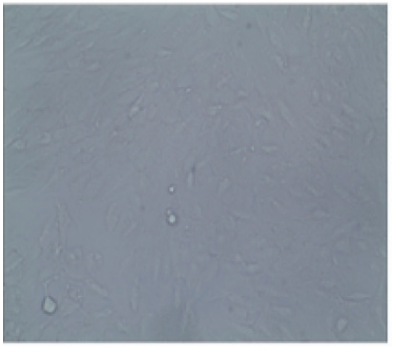

Nomorxia

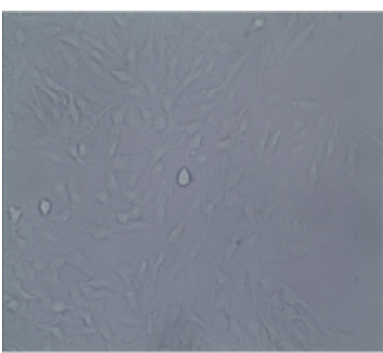

Hypoxia+SYD+miR-24 mimic

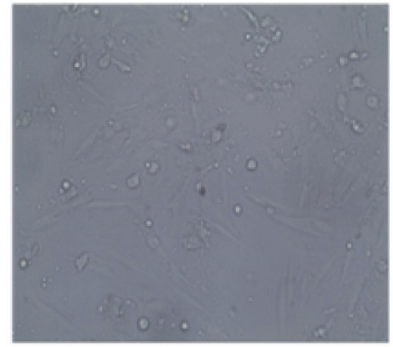

Hypoxia

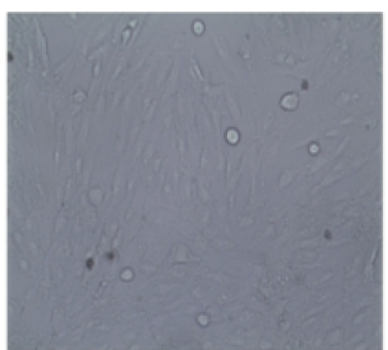

Hypoxia+SYD+miR-24 inhibitor

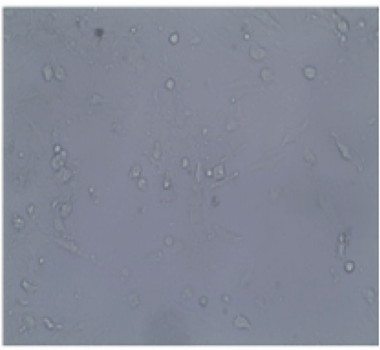

Hypoxia+SYD

(a)

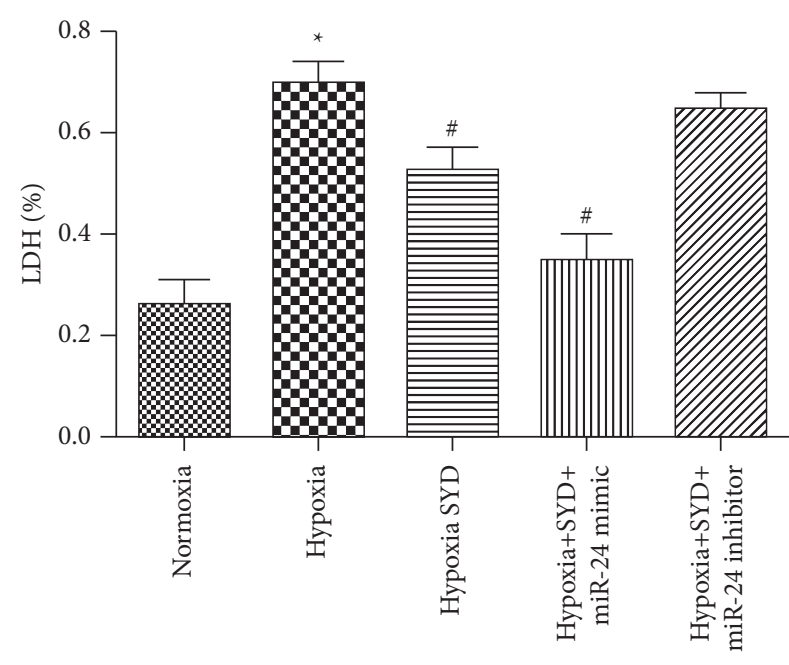

(b)

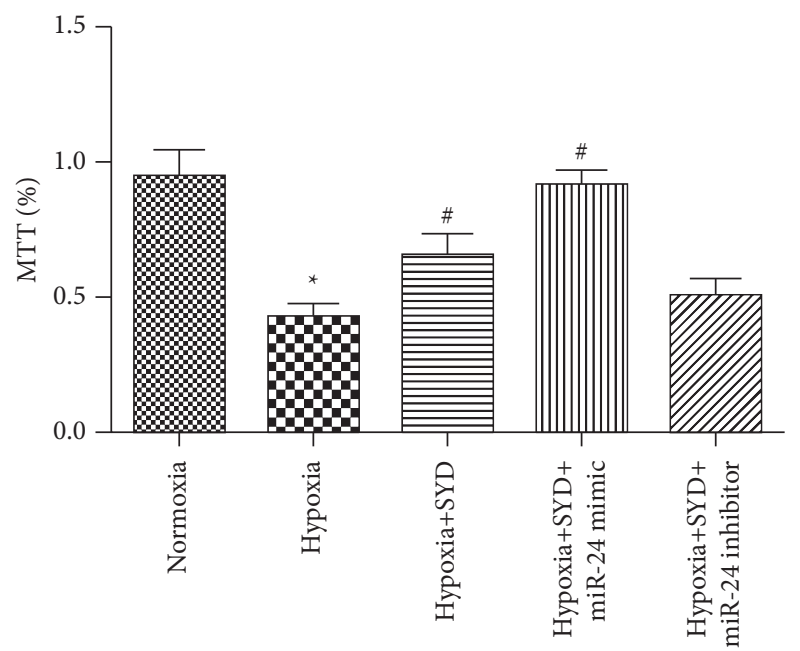

(d)

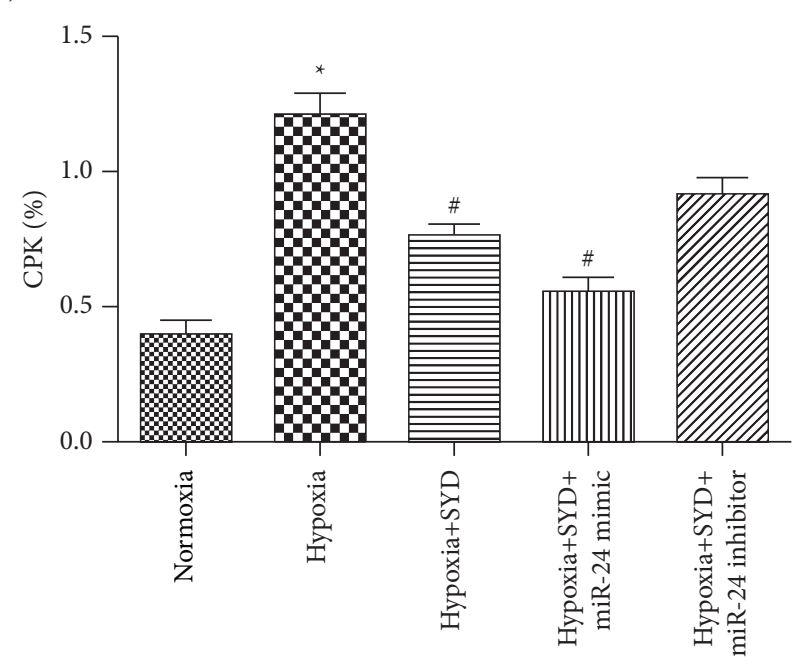

(c)

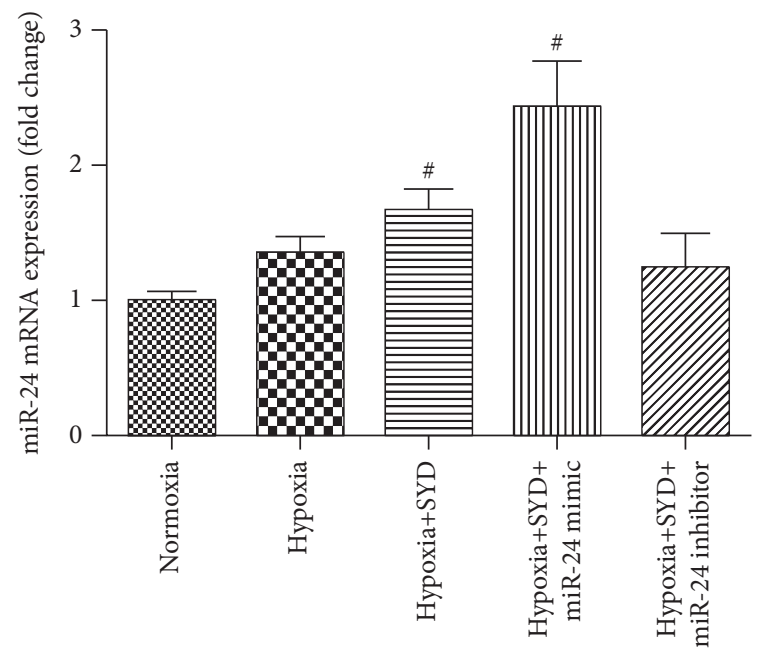

(e)

FIGURE 1: Effects of SYD on hypoxia-induced cardiomyocyte morphology, cell injury, cell viability, and miR-24 expression. (a) After 48 hours of hypoxia, the morphology of myocardial cells changed from spindle to round or quasi-round. (b, c) SYD could reduce LDH and CPK activity of hypoxia myocardial cells. (d) Cardiomyocytes viability was examined by MTT assay. (e) The expression of miR-24 was detected by qRT-PCR. Data are expressed as the mean \pm SEM $(n=3) .{ }^{\star} P<0.05$ versus Normoxia group; ${ }^{\#} P<0.05$ versus Hypoxia group. 

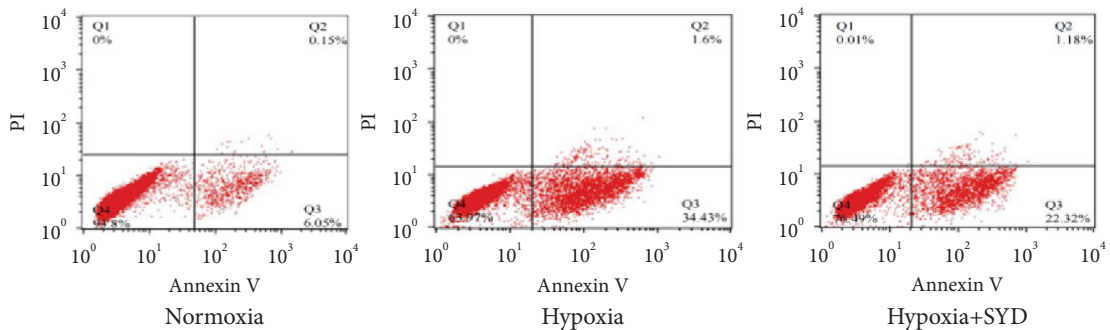

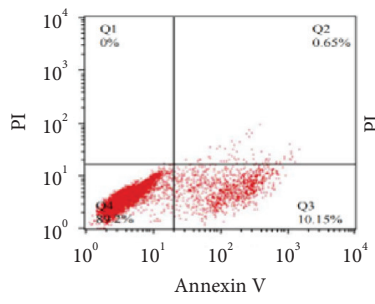

Hypoxia+SYD+miR-24 mimic

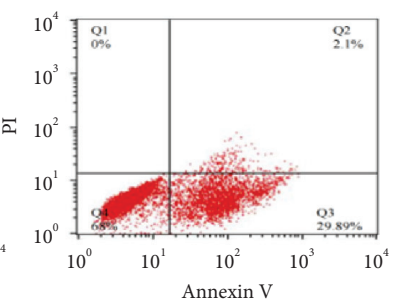

Hypoxia+SYD+miR-24 inhibitor

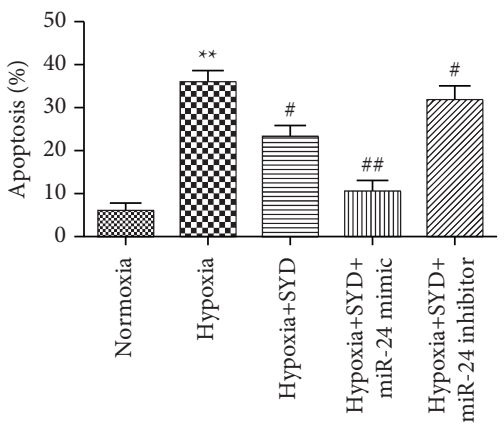

(a)

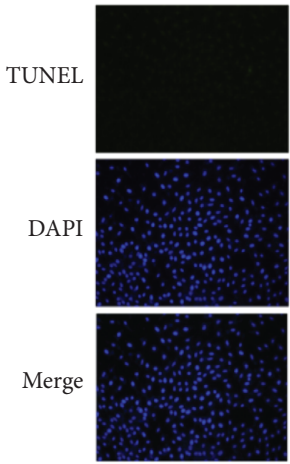

Nomorxia

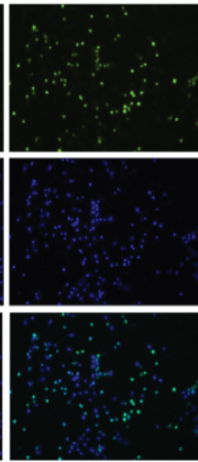

Hypoxia

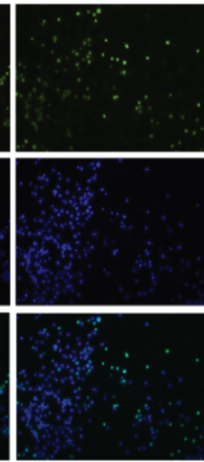

Hypoxia+SYD

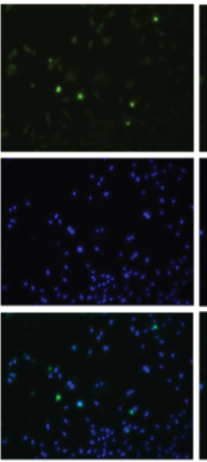

Hypoxia+SYD+ miR-24 mimic

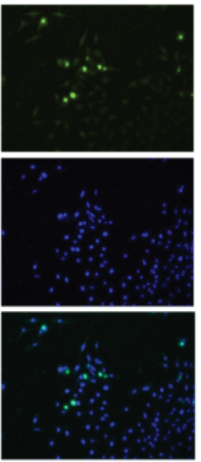

Hypoxia+SYD+ miR-24 inhibitor

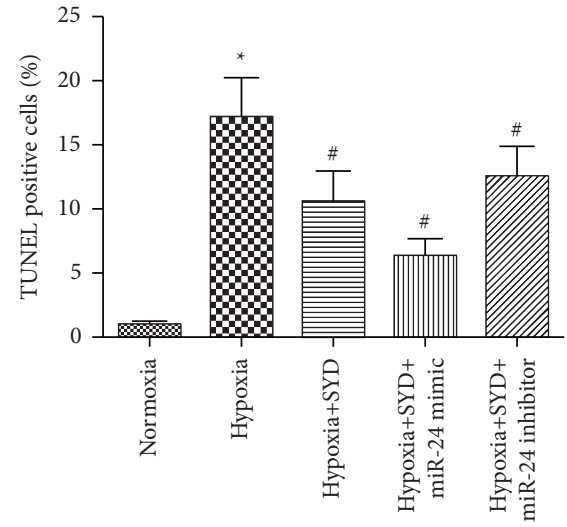

(b)

FIGURE 2: Effects of SYD on hypoxia-induced cardiomyocyte apoptosis. (a) Detection of hypoxia-induced cardiomyocyte apoptosis by flow cytometry. (b) Detection of hypoxia-induced cardiomyocyte apoptosis by TUNEL staining. Data are expressed as the mean \pm SEM $(n=3)$. ${ }^{\star} P<0.05$ and ${ }^{\star \star} P<0.01$ versus Normoxia group; ${ }^{\#} P<0.05$ and ${ }^{\# \#} P<0.01$ versus Hypoxia group.

activity of the Bim gene (Figures 4(a) and 4(b)), indicating that miR-24 regulates its expression by directly targeting the $3^{\prime}$ UTR of the Bim gene. Meanwhile, western blot analysis showed that Bim protein expression was significantly decreased after transfection with miR-24 in the neonatal rat cardiomyocytes (Figures 4(c) and 4(d)). These results indicated that miR-24 can inhibit Bim expression by binding to the $3^{\prime}$ UTR of Bim.

\section{Discussion}

The present study revealed that SYD treatment can effectively alleviate hypoxia-induced neonatal rat cardiomyocyte injury, improve cell viability, inhibit cardiomyocyte apoptosis, and regulate the expression of apoptotic-related factors of the mitochondrial cell apoptosis pathway. Furthermore, our results confirmed that Bim is the direct target gene of miR-24 and that the upregulation of miR-24 expression in cardiomyocytes can significantly inhibit the target gene Bim and enhance the protective effect of SYD, thereby reducing myocardial cell apoptosis. Finally, our results confirmed that SYD can play a protective role in reducing hypoxia-induced cardiomyocyte apoptosis by upregulating miR-24 expression and inhibiting the expression of its target gene Bim.

Apoptosis is a key pathological mechanism following AMI and is mediated by the mitochondrial pathway, in which the interaction among the $\mathrm{Bcl}-2$ protein family members plays a key role in regulating apoptosis [3]. When hypoxia or ischemia occurs, pro-apoptotic proteins (Bad and Bax) are translocated to the mitochondria, which induce the downregulation or degradation of Bcl-2 and Bcl$\mathrm{xL}$, eventually increasing the release of mitochondrial cytochrome C (Cyt-C). When Cyt-C is released from the mitochondria, it changes conformation with APaf-1 (apoptosis protein-activated factor) in the presence of ATP/ dATP and forms a large structure called an apoptosome. Simultaneously, the apoptosome attracts Caspase- 9 precursors, and Caspase- 9 is activated through trans-catalysis after polymerisation with the apoptosome structure. The 


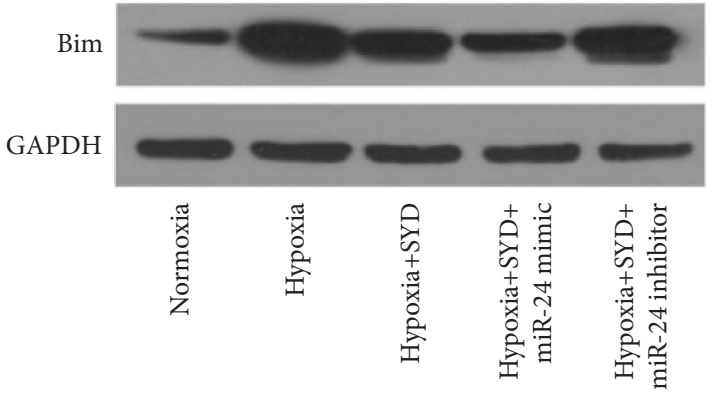

(a)

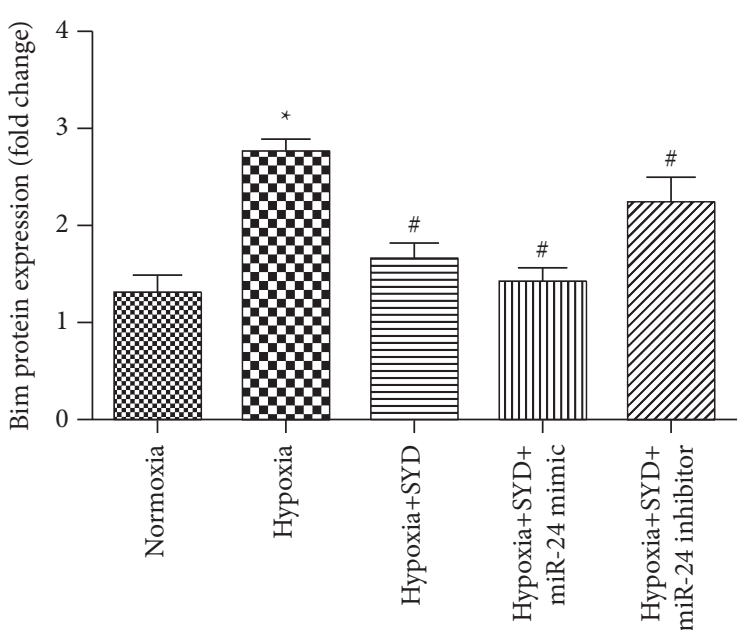

(b)

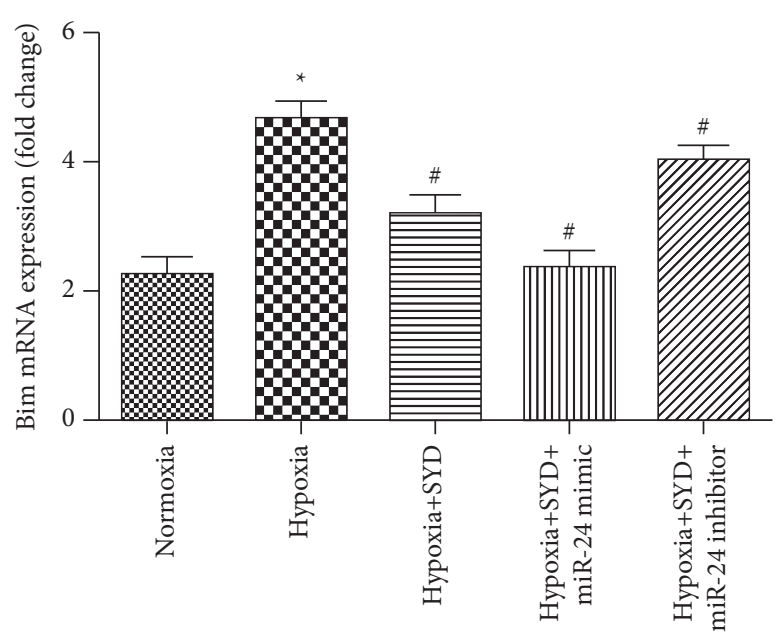

(c)

FIGURE 3: Effect of SYD on the expression of Bim protein and mRNA in hypoxia-induced cardiomyocyte. (a) The expression of Bim protein was analyzed by western blotting. (b) SYD can decrease the expression of Bim protein in hypoxia-induced cardiomyocyte. (c) SYD can decrease the expression of Bim mRNA in hypoxia-induced cardiomyocyte. Data are expressed as the mean \pm SEM $(n=3)$. ${ }^{\star} P<0.05$ versus Normoxia group; ${ }^{\#} P<0.05$ versus Hypoxia group.

activated Caspase- 9 then acts on the downstream Caspase3, Caspase-6, and Caspase-7, thereby activating the caspase-cascade and causing apoptosis. For terminally differentiated cardiomyocytes lacking the regenerative capacity, apoptosis of myocardial cells after MI should be decreased for promoting the recovery of cardiac function and delaying the incidence of heart failure after MI. The results of our study demonstrated that after $48 \mathrm{~h}$ of hypoxia, the LDH and CPK activities were obviously increased, the cell viability was decreased, and the myocardial cell apoptosis was significantly increased. SYD can effectively reduce the activities of LDH and CPK, improve myocardial cell viability, and inhibit cell apoptosis in hypoxia-induced cardiomyocytes. Our study also indicated that SYD intervention could decrease the gene and protein expression of pro-apoptotic factor Bim. These results confirm that SYD can play a protective role in myocardium by reducing hypoxia-induced apoptosis of the cardiomyocytes.
Studies have shown that miR-24, which is highly expressed in the mammalian myocardium and other tissues, can participate in the pathological process of various cardiovascular diseases such as myocardial hypertrophy, apoptosis, myocardial fibrosis, and cardiac remodeling by regulating the translation and expression of its target genes [43-46]. Li et al. [47] found that miR-24, which is highly expressed in heart failure and myocardial hypertrophy models, can suppress the stress response of cardiomyocytes by inhibiting the expression of its target gene JP2, whereas the downregulation of miR-24 was found to stabilize JP2 protein expression, thereby stabilizing the electrophysiological process and stress response of cardiomyocytes. Qian et al. [10] found that miR-24 can regulate the apoptosis of myocardial cells after MI by targeting the expression of Bim pro-apoptotic genes. After MI, miR-24 expression in the myocardial tissues of the infarction area is significantly reduced, and upregulation of miR-24 expression can reduce the apoptosis of myocardial cells in the infarction 

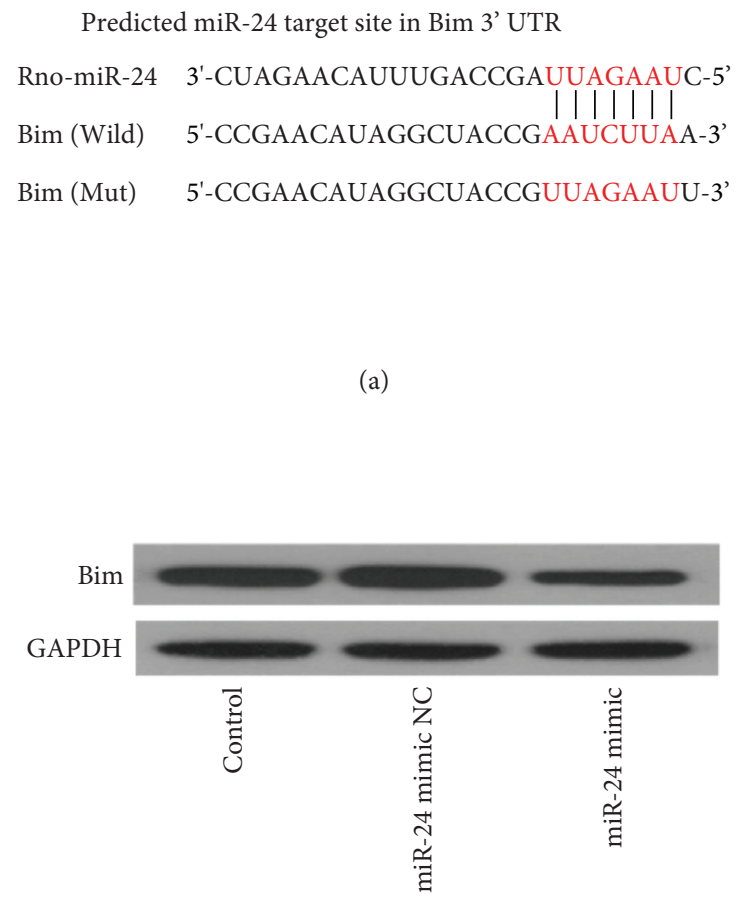

(c)

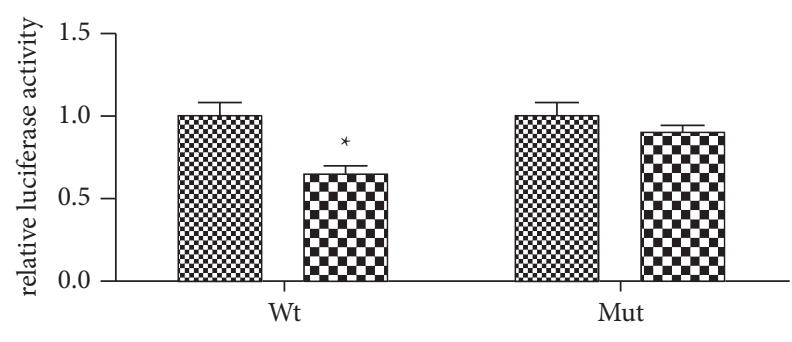

\% NC

$0 \mathrm{miR}-24$

(b)

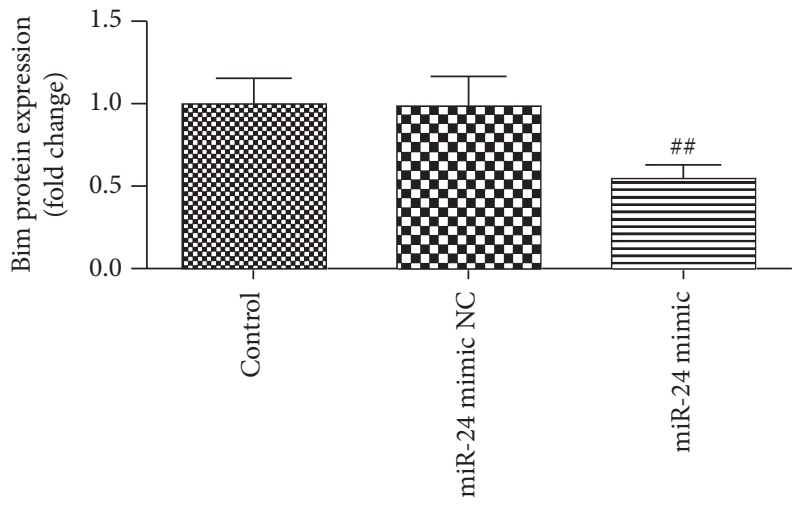

(d)

FIgURE 4: Bim is the direct target gene of miR-24. (a) Schematic description of the base-pairing interaction between miR-24 and Bim mRNA. (b) Luciferase reporter assay was performed in neonatal rat cardiomyocytes that were cotransfected with miR-24 mimics or NC-mimics together with reporter vectors containing Bim $3^{\prime}$ UTR or mutated Bim 3'UTR. Relative luciferase activities were presented. (c, d) Western blot analysis showed that the expression of Bim protein was significantly decreased after transfection with miR-24 mimic in neonatal rat cardiomyocytes. ${ }^{\star} P<0.05$ versus NC group; ${ }^{\# \#} P<0.01$ versus miR-24 mimic NC group.

area. All the aforementioned studies suggest that miR-24 may be a protective factor involved in the pathology of myocardial cell injury and repair after MI. In this study, we first found that hypoxia causes myocardial cell injury and upregulation of miR24. SYD treatment significantly improved myocardial cell injury induced by hypoxia. Interestingly, the expression level of miR-24 was further increased in response to SYD treatment in hypoxic surroundings. To investigate the role of miR-24 in myocardial cell injury, miR-24 mimics or inhibitors were transfected to hypoxia + SYD-treated myocardial cells. The result showed that transfection of miR-24 mimics further improved myocardial cell injury, while transfection of miR-24 inhibitors enhanced myocardial cell injury. Therefore, miR-24 plays a protective role in hypoxia-mediated myocardial cell injury.

According to Chinese medical theory, AMI falls within the scope of "True Heart Pain," and the "Qi deficiency and blood stasis syndrome" is the most common syndrome in TCM clinical practice. Tonifying Qi and expelling stasis are highly significant in the treatment of CHD. SYD is a TCM herbal compound preparation that invigorates Qi and removes blood stasis. This preparation comprises Astralgus membranaceus Bge, Radix Pilose Asiabell, Radix Scrophulariae, Salvia miltiorrhiza Bge, Lumbricus, Eupolyphaga sinensis, Hirudo nipponica, and Rhizoma Corydalis. Studies have reported that SYD can effectively reduce the plasma
$\mathrm{LDH}$ and CK-MB levels in rats with ischemia/reperfusion injury, prevent lipid peroxidation injury, inhibit inflammatory response, and slow down the expansion of infarct after MI in rats. SYD can also increase the activity of myocardial cells induced by hypoxia/reoxygenation [13]. Our previous in vivo experiments also indicated that SYD can effectively reduce the myocardial apoptosis rate in MI rats, increase miR24 expression, and play an anti-apoptosis role by inhibiting the expressions of the target gene Bim and downstream proapoptotic factors [42]. In this study, we found that SYD can alleviate hypoxia-induced injury and reduce apoptosis of neonatal rat myocardial cells. In addition, we found that the inhibitory effect of SYD on apoptosis was further enhanced after transfection with an miR-24 mimic, whereas this protective effect was significantly weakened after transfection with an miR-24 inhibitor. Based on these results, we can conclude that the mechanism for the decreased hypoxia-induced apoptosis of cardiomyocytes caused by SYD may be related to the upregulation of miR-24 expression and the inhibition of the expression of its target gene Bim.

\section{Conclusion}

SYD can alleviate hypoxia-induced neonatal rat cardiomyocyte injury, decrease LDH and CPK activities, increase cell viability, and reduce cell apoptosis. Meanwhile, 
our results confirmed that SYD could upregulate miR-24 expression and downregulate mitochondrial apoptotic pathway pro-apoptotic factor Bim expression. Bioinformatics analysis and luciferase reporter assays showed that Bim is the direct target gene of miR-24. Moreover, upregulation of miR-24 expression could significantly inhibit the expression of the target gene Bim, thereby enhancing the effect of SYD and decreasing myocardial cell apoptosis in the neonatal rat cardiomyocytes. Our results highlight that SYD treatment can reduce hypoxia-induced myocardial apoptosis by upregulating miR-24 expression. This study offers novel insights into the molecular mechanism underlying the therapeutic potential of SYD in promoting the recovery of myocardial function and delaying heart failure incidence.

$\begin{array}{ll}\text { Abbreviations } \\ \text { SYD: } & \text { Shen-yuan-dan } \\ \text { AMI: } & \text { Acute myocardial infarction } \\ \text { miRNAs: } & \text { MicroRNAs } \\ \text { TCM: } & \text { Traditional Chinese medicine } \\ \text { UPLC-MS/ } & \text { Ultra-high-performance liquid } \\ \text { MS: } & \text { chromatography-tandem mass spectrometry } \\ \text { DMSO: } & \text { Dimethylsulfoxide } \\ \text { qRT-PCR: } & \text { Quantitative real-time PCR } \\ \text { LDH: } & \text { Lactic dehydrogenase } \\ \text { CPK: } & \text { Creatine phosphokinase. }\end{array}$

\section{Data Availability}

The datasets used and/or analyzed during the current study are available from the corresponding author on reasonable request.

\section{Ethical Approval}

Not applicable.

\section{Conflicts of Interest}

The authors declare no conflicts of interest.

\section{Authors' Contributions}

Fuyong Chu and Hongxu Liu designed, organized, and supervised the study. Fuyong Chu, Xue Yan, Xingjiang Xiong, Mingxue Zhou, Yupei Tan, Yixuan Li, and Wei Liu drafted the manuscript. Yupeii Tan, Yixuan Li, and Xingjiang Xiong analyzed the literature. Fuyong Chu revised the manuscript. Wei Liu and Hongxu Liu participated in the revision. All authors read and approved the final manuscript.

\section{Acknowledgments}

This research was supported by the (https://doi.org/10. 13039/501100001809National Natural Science Foundation of China (Nos. 81603561 and 82174315), (https://doi.org/10. 13039/501100005089Beijing Natural Science Foundation (No. 7194277), and Fund for Evidence-Based Capacity
Building Project of Chinese Medicine Administration of the People's Republic of China (2019XZZX-XXG001).

\section{References}

[1] Y. Castro-Dominguez, K. Dharmarajan, and R. L. McNamara, "Predicting death after acute myocardial infarction," Trends in Cardiovascular Medicine, vol. 28, no. 2, pp. 102-109, 2018.

[2] Q. Zhao, Y. Yang, Z. Chen, H. Yu, and H. Xu, "Changes in characteristics, risk factors, and in-hospital mortality among patients with acute myocardial infarction in the capital of China over 40 years," International Journal of Cardiology, vol. 265, pp. 30-34, 2018.

[3] X. Wang, Z. Guo, Z. Ding, and J. L Mehta, "Inflammation, autophagy, and apoptosis after myocardial infarction," Journal of American Heart Association, vol. 7, no. 9, Article ID e008024, 2018.

[4] X. Wang, X. He, S. Hu, A. Sun, and C. Lu, "Involvement of bim in photofrin-mediated photodynamically induced apoptosis," Cellular Physiology and Biochemistry, vol. 35, no. 4, pp. 1527-1536, 2015.

[5] L.-N. Zhang, J.-Y. Li, and W. Xu, "A review of the role of Puma, Noxa and Bim in the tumorigenesis, therapy and drug resistance of chronic lymphocytic leukemia," Cancer Gene Therapy, vol. 20, no. 1, pp. 1-7, 2013.

[6] Y.-h. Gao, J.-y. Qian, Z.-w. Chen et al., "Suppression of Bim by microRNA-19a may protect cardiomyocytes against hypoxiainduced cell death via autophagy activation," Toxicology Letters, vol. 257, no. 257, pp. 72-83, 2016.

[7] X. Wang, T. Ha, Y. Hu et al., "MicroRNA-214 protects against hypoxia/reoxygenation induced cell damage and myocardial ischemia/reperfusion injury via suppression of PTEN and Bim1 expression," Oncotarget, vol. 7, no. 35, pp. 86926-86936, 2016.

[8] J. Wang, S. Yan, and J. Yang, "Non-coding RNAs in rheumatoid arthritis: from bench to bedside," Frontiers in Immunology, vol. 10, p. 3129, 2020.

[9] J. Gao, M. Zhu, R.-F. Liu, J.-S. Zhang, and M. Xu, "Cardiac hypertrophy is positively regulated by microRNA-24 in rats," Chinese Medical Journal, vol. 131, no. 11, pp. 1333-1341, 2018.

[10] L. Qian, L. W. Van Laake, Y. Huang, S. Liu, M. F. Wendland, and D. Srivastava, "miR-24 inhibits apoptosis and represses Bim in mouse cardiomyocytes," Journal of Experimental Medicine, vol. 208, no. 3, pp. 549-560, 2011.

[11] W. Minghua, G. Zhijian, H. Chahua et al., "Plasma exosomes induced by remote ischaemic preconditioning attenuate myocardial ischaemia/reperfusion injury by transferring miR24," Cell Death \& Disease, vol. 9, no. 3, p. 320, 2018.

[12] F. Y. Chu, H. X. Liu, and M. Chen, "Association of miR-24 expression in peripheral blood with apoptosis and inflammatory cytokines in ACS patients," Chinese Journal of Geriatric Heart Brain Vessel Disease, vol. 18, no. 8, pp. 808-811, 2016.

[13] H. Liu, J. Shang, F. Chu et al., "Protective effects of ShenYuan-Dan, a traditional Chinese medicine, against myocardial ischemia/reperfusion injury in vivo and in vitro," Evidence-Based Complementary and Alternative Medicine, vol. 2013, Article ID 956397, 11 pages, 2013.

[14] M. Zhou, P. Ren, Y. Zhang et al., "Shen-yuan-dan capsule attenuates atherosclerosis and foam cell formation by enhancing autophagy and inhibiting the PI3K/Akt/mTORC1 signaling pathway," Frontiers in Pharmacology, vol. 10, p. 603, 2019.

[15] C. Lim, S. Lim, B. Lee, B. Kim, and S. Cho, "Effect of methanol extract of Salviae miltiorrhizae Radix in high-fat diet-induced hyperlipidemic mice," Chinese Medicine, vol. 12, p. 29, 2017. 
[16] W. Li, Y.-h. Jiang, Y. Wang et al., "Protective effects of combination of radix astragali and radix salviae miltiorrhizae on kidney of spontaneously hypertensive rats and renal intrinsic cells," Chinese Journal of Integrative Medicine, vol. 26, no. 1, pp. 46-53, 2020.

[17] Y. H. Li, F. Y. Wang, C. Q. Feng, and X. F. Yang, "Studies on the active constituents in radix salviae miltiorrhizae and their protective effects on cerebral ischemia reperfusion injury and its mechanism," Pharmacognosy Magazine, vol. 11, no. 41, pp. 69-73, 2015.

[18] R. Lin, J. Duan, F. Mu et al., "Cardioprotective effects and underlying mechanism of Radix Salvia miltiorrhiza and Lignum Dalbergia odorifera in a pig chronic myocardial ischemia model," International Journal of Molecular Medicine, vol. 42, no. 5, pp. 2628-2640, 2018.

[19] W. Zhao, Y. Yuan, H. Zhao, Y. Han, and X. Chen, "Aqueous extract of Salvia miltiorrhiza Bunge-Radix Puerariae herb pair ameliorates diabetic vascular injury by inhibiting oxidative stress in streptozotocin-induced diabetic rats," Food and Chemical Toxicology, vol. 129, pp. 97-107, 2019.

[20] Q. Zheng, J. Z. Zhu, and X. Y. Bao, “A preclinical systematic review and meta-analysis of Astragaloside IV for myocardial ischemia/reperfusion injury," Frontiers in Physiology, vol. 9, p. 795, 2018.

[21] M. Shahzad, A. Shabbir, K. Wojcikowski, H. Wohlmuth, and G. Gobe, "The antioxidant effects of Radix Astragali (Astragalus membranaceus and Related Species) in protecting tissues from injury and disease," Current Drug Targets, vol. 17, no. 12, pp. 1331-1340, 2016.

[22] D. Das, S. Biswal, K. K. Barhwal et al., "Methanolic root extract of Codonopsis clematidea prevents hypoxia induced procoagulant state by inhibition of GPIb receptor regulated Lyn kinase activation," Phytomedicine: International Journal of Phytotherapy and Phytopharmacology, vol. 59, Article ID 152903, 2019.

[23] C. Liu, Y. Wang, and Y. Shi, "Effect of sulfur fumigation on immune function of mice," Chinese Herbal Medicine, vol. 37, no. 11, pp. 1969-1972, 2014.

[24] J. Lee, K.-J. Kim, Y.-H. Kim et al., "Codonopsis lanceolata extract prevents diet-induced obesity in C57BL/6 mice," Nutrients, vol. 6, no. 11, pp. 4663-4677, 2014.

[25] J. Liao, C. Hao, W. Huang et al., "Network pharmacology study reveals energy metabolism and apoptosis pathwaysmediated cardioprotective effects of Shenqi Fuzheng," Journal of Ethnopharmacology, vol. 227, pp. 155-165, 2018.

[26] Y. Chen, L. Zhang, and X. Gong, "Iridoid glycosides from Radix Scrophulariae attenuates focal cerebral ischemiareperfusion injury via inhibiting endoplasmic reticulum stress-mediated neuronal apoptosis in rats," Molecular Medicine Reports, vol. 21, no. 1, pp. 131-140, 2020.

[27] X. Meng, W. Xie, and Q. Xu, "Neuroprotective effects of radix Scrophulariae on cerebral ischemia and reperfusion injury via MAPK pathways," Molecules, vol. 23, no. 9, p. 2401, 2018.

[28] M. Alaee, A. Akbari, H. Karami, Z. Salemi, J. Amri, and M. Panahi, "Antidiabetic and protective effects of Scrophularia striata ethanolic extract on diabetic nephropathy via suppression of RAGE and S100A8 expression in kidney tissues of streptozotocin-induced diabetic rats," Journal of Basic and Clinical Physiology and Pharmacology, vol. 31, no. 2, Article ID 20190186, 2020.

[29] C. Chen, C. Chen, and X. Wu, "Effects of extracts of Radix Scrophulariae on blood pressure in spontaneously hypertensive rats and the underlying mechanisms," Journal of Chinese Integrative Medicine, vol. 10, no. 9, pp. 1009-1017, 2012.
[30] L. Ouyang, X. Hu, and M. Niu, "Mechanisms of Hirudo in promoting blood circulation and removing stasis based on network pharmacology," China Journal of Chinese Materia Medica, vol. 43, no. 9, pp. 1901-1906, 2018.

[31] S. Li, L. Cheng, D. An et al., "Whitmania Pigra Whitman extracts inhibit Lipopolysaccharide induced rat vascular smooth muscle cells migration and their adhesion ability to THP-1 and RAW 264.7 Cells," Journal of Atherosclerosis and Thrombosis, vol. 24, no. 3, pp. 301-311, 2017.

[32] X.-1. Yao, H. Liu, P. Li et al., "Aqueous extract of whitmania pigra whitman alleviates thrombus burden via sirtuin $1 / \mathrm{NF}$ «B pathway," Journal of Surgical Research, vol. 245, pp. 441-452, 2020.

[33] X. Wang, M. Niu, S. N. Wu et al., "Leeches attenuate blood hyperviscosity and related metabolic disorders in rats differently than aspirin," Journal of Ethnopharmacology, vol. 238, Article ID 111813, 2019.

[34] Y. Wu, Y. Ma, S. Hu et al., "Transcriptomic-proteomicsanticoagulant bioactivity integrated study of Pheretima guillemi," Journal of Ethnopharmacology, vol. 243, Article ID 112101, 2019.

[35] P. C. Huang, M. A. Shibu, C. H. Kuo et al., "Pheretima aspergillum extract attenuates high-KCl-induced mitochondrial injury and pro-fibrotic events in cardiomyoblast cells," Environmental Toxicology, vol. 34, no. 8, pp. 921-927, 2019.

[36] Z. Y. Sun, F. J. Wang, H. Guo et al., "Shuxuetong injection protects cerebral microvascular endothelial cells against oxygen-glucose deprivation reperfusion," Neural Regeneration Research, vol. 14, no. 5, pp. 783-793, 2019.

[37] W. Wang, J. Wang, and D. Zhao, "Comparison of lipid regulating effects of Caulis," China Journal of Chinese medicine, vol. 16, no. 5, pp. 299-320, 1991.

[38] B. Dai, J. Qi, R. Liu, and Y. Zhang, "Eupolyphaga sinensis Walker demonstrates angiogenic activity and inhibits A549 cell growth by targeting the KDR signaling pathway," Molecular Medicine Reports, vol. 10, no. 3, pp. 1590-1596, 2014.

[39] S. Chang, Z. Yang, N. Han, Z. Liu, and J. Yin, "The antithrombotic, anticoagulant activity and toxicity research of ambinine, an alkaloid from the tuber of Corydalis ambigua var. amurensis," Regulatory Toxicology and Pharmacology, vol. 95, pp. 175-181, 2018.

[40] X.-T. Zhai, J.-Q. Chen, C.-H. Jiang et al., "Corydalis bungeana Turcz. attenuates LPS-induced inflammatory responses via the suppression of NF- $\kappa \mathrm{B}$ signaling pathway in vitro and in vivo," Journal of Ethnopharmacology, vol. 194, pp. 153-161, 2016.

[41] M. Xue, M.-L. Liu, X.-Y. Zhu, D.-Z. Shi, and H.-J. Yin, "Effective components of Panax quinquefolius and Corydalis tuber protect the myocardium by inhibiting platelet activation and improving the hypercoagulable state," Experimental and Therapeutic Medicine, vol. 9, no. 4, pp. 1477-1481, 2015.

[42] F. Chu, W. Liu, and H. Liu, "Effects of Yiqi Zhuyu formula on myocardial injury markers and miR-24 gene expression in rats with myocardial infarction," Beijing Journal of Traditional Chinese Medicine, vol. 34, no. 3, pp. 187-189, 2015.

[43] M. Xu, H.-D. Wu, R.-C. Li et al., "miR-24 regulates junctophilin-2 expression in cardiomyocytes," Circulation Research, vol. 111, no. 7, pp. 837-841, 2012.

[44] J. Wang, W. Huang, R. Xu et al., "MicroRNA-24 regulates cardiac fibrosis after myocardial infarction," Journal of Cellular and Molecular Medicine, vol. 16, no. 9, pp. 2150-2160, 2012.

[45] D.-F. Li, J. Tian, X. Guo et al., "Induction of microRNA-24 by HIF-1 protects against ischemic injury in rat cardiomyocytes," Physiological Research, vol. 61, pp. 555-565, 2012. 
[46] C. Guo, Y. Deng, J. Liu, and L. Qian, "Cardiomyocyte-specific role of miR-24 in promoting cell survival," Journal of Cellular and Molecular Medicine, vol. 19, no. 1, pp. 103-112, 2015.

[47] R.-C. Li, J. Tao, Y.-B. Guo et al., "In vivo suppression of microRNA-24 prevents the transition toward decompensated hypertrophy in aortic-constricted mice," Circulation Research, vol. 112, no. 4, pp. 601-605, 2013. 